\title{
ADAM10: a new player in breast cancer progression?
}

\author{
Maeve Mullooly ${ }^{\star 1,2}$, Patricia M McGowan ${ }^{1,2}$, Susan A Kennedy ${ }^{3}$, Stephen F Madden ${ }^{4}$, John Crown ${ }^{4,5}$, \\ Norma O' Donovan ${ }^{4}$ and Michael J Duffy ${ }^{1,6}$ \\ ${ }^{1}$ UCD School of Medicine and Medical Science, Conway Institute of Biomolecular and Biomedical Research, University College \\ Dublin, Dublin, Ireland; ${ }^{2}$ Education and Research Centre, St. Vincent's University Hospital, Dublin, Ireland; ${ }^{3}$ Systems Biology \\ Ireland, Conway Institute of Biomolecular and Biomedical Research, University College Dublin, Dublin, Ireland; ${ }^{4}$ National Institute \\ for Cellular Biotechnology (NICB), Dublin City University, Dublin, Ireland; ${ }^{5}$ Department of Medical Oncology, St. Vincent's \\ University Hospital, Dublin, Ireland and ${ }^{6}$ UCD Clinical Research Centre, St. Vincent's University Hospital, Dublin, Ireland
}

Background: The ADAM proteases are best known for their role in shedding the extracellular domain of transmembrane proteins. Among the transmembrane proteins shed by ADAM10 are notch, HER2, E-cadherin, CD44, L1 and the EGFR ligands, EGF and betacellulin. As cleavage of several of these proteins has been implicated in cancer formation and progression, we hypothesised that ADAM10 is also involved in these processes.

Methods: ADAM10 expression was decreased by RNA interference and the effects of this on cell numbers, invasion and migration were determined. We also examined the effect of ADAM10 inhibition on breast cancer cell line invasion and migration.

Results: Using the triple-negative (TN) breast cancer cell lines, BT20, MDA-MB-231 and the non-TN cell line MDA-MB-453, knockdown of ADAM10 expression significantly decreased in vitro migration $(P<0.01$; for each cell line). Similarly, treatment with the ADAM10-selective inhibitor GI254023X reduced migration in the three cell lines (for BT20, $P<0.001$; for MDA-MB-231, $P=0.005$; for MDA-MB-453, $P=0.023$ ). In contrast, neither knockdown of ADAM10 nor treatment with the ADAM10-selective inhibitor GI254023X significantly affected cell numbers. Using extracts of primary breast cancers, higher levels of ADAM10 were found more frequently in high-grade vs low-grade tumours $(P<0.001)$ and in oestrogen receptor (ER)-negative compared with ERpositive tumours $(P=0.005)$. Analysis of pooled publicly available data sets found that high levels of ADAM10 mRNA were associated with adverse outcome in patients with the basal subtype of breast cancer.

Conclusions: Based on our combined cell line and breast cancer extract data, we conclude that ADAM10 is likely to be involved in breast cancer progression, especially in the basal subtype.

The ADAMs are a family of multifunctional proteins implicated in proteolysis and cell adhesion (Blobel, 2005; Murphy, 2008; Duffy et al, 2009). Unlike the matrix-degrading proteases such as the matrix metalloproteases and urokinase plasminogen activator, the main substrates for ADAM proteases are the extracellular domains of transmembrane proteins. Of the 21 human ADAMs, one of the most-detailed studied is ADAM17 (Sahin et al, 2004; Blobel, 2005; Murphy, 2008; Duffy et al, 2009). ADAM17 is involved in the release and activation of several growth factors and cytokine receptor ligands. Among the growth factors activated by ADAM17 are TGF-alpha, amphiregulin, epiregulin and HB-EGF (Sahin and Blobel, 2007; McGowan et al, 2007). Because of its ability to activate these growth factors and thus stimulate EGFR signalling systems, ADAM17 have been implicated in cancer progression (Blobel, 2005; Murphy, 2008; Duffy et al, 2009). Indeed, in several different tumour model systems, ADAM17 has been shown to enhance cell proliferation, invasion and migration (Borrell-Pages et al, 2003; Franovic et al, 2006; Kenny and Bissell, 2007; McGowan et al, 2007). These effects of ADAM17 are likely to be at least partly mediated by release of the 
EGFR/HER ligands, which in turn activates EGFR signalling (Sahin and Blobel, 2007).

An ADAM structurally and functionally related to ADAM17 is ADAM10 (Duffy et al, 2003; Moss et al, 2008). Like ADAM17, ADAM10 has also been implicated in the activation of specific EGFR ligands, especially EGF and betacellulin (Sahin and Blobel, 2007). However, in addition to releasing these EGFR ligands, ADAM10 has also been shown to activate notch signalling (Hartmann et al, 2002; Bozhulak and Weinmaster, 2009; Weber et al, 2011) and cleave the extracellular domains of adhesion proteins, such as E-cadherin (Maretzky et al, 2005a, b; Solanas et al, 2011), N-cadherin, L1 and CD44 (Mechtersheimer et al, 2001; Hundhausen et al, 2003; Reiss et al, 2005; Maretzky et al, 2005a, b; Murai et al, 2006). The ability of ADAM10 to activate notch and EGFR signalling as well as cleave several adhesion proteins suggests that ADAM10, similar to ADAM17, may also have a role in cancer progression.

In contrast to ADAM17, little detailed work has been carried out on ADAM10 in cancer (Arima et al, 2007; Lee et al, 2010; Gaida et al, 2010), especially in breast cancer. In one of the few reports on ADAM10 in breast cancer, Feldinger et al (2014) recently reported that elevated expression of this ADAM predicted resistance to trastuzumab (Herceptin). ADAM10 may thus have a clinical role in breast cancer.

The aim of this study was therefore to perform a detailed investigation on ADAM10 in breast cancer. Here we show that inhibition of ADAM10 expression using RNA interference or blockage of its activity using a selective low molecular weight inhibitor significantly decreased breast cancer cell line invasion and migration. We also show that ADAM10 protein levels were significantly elevated in high-grade compared with low-grade tumours and in oestrogen receptor (ER)-negative compared with ER-positive tumours. In addition, we found that high expression of ADAM10 predicted poor outcome in patients with basal-type breast cancer. Our preclinical results, when combined with those from extracts of human cancers, suggest that ADAM10 is involved in the progression of breast cancer.

\section{MATERIALS AND METHODS}

Cell lines and reagents. The breast cancer cell lines BT20, MDA-MB-231 and MDA-MB-453 were obtained from the American Tissue Culture Collection (Manassas, VA, USA). Cell lines were cultured in RPMI 1640, supplemented with 10\% fetal bovine serum (Invitrogen Life Sciences, Carlsbad, CA, USA) and maintained in a $37^{\circ} \mathrm{C} \mathrm{CO}_{2}$-humidified incubator. Cell line identity was confirmed by analysis of Short Tandem Repeat Loci (IdentiCell, Aarhus, Denmark). Cells were routinely tested for mycoplasma infection. The ADAM10 selective inhibitor GI254023X (Hundhausen et al, 2003; Ludwig et al, 2005) was obtained from GlaxoSmithKline (GlaxoSmithKline UK Ltd, Stevenage, UK) via material transfer agreement. A ten millimolar stock solution was prepared and stored at $4{ }^{\circ} \mathrm{C}$.

RNA interference. All cell lines were transiently transfected using the reverse transfection method with commercially available ADAM10 siRNA pooled sequences (Dharmacon, Thermo Fisher Scientific, Lafayette, CO, USA; Thermo Scientific, Rockford, IL, USA). Briefly, a $20-\mu \mathrm{m}$ stock solution of ADAM10 siRNA was prepared in siRNA buffer according to the manufacturer's instructions. ADAM10 siRNA solution (50-75 nM) or corresponding scrambled control siRNA were incubated in Opti-MEM (Invitrogen Life Sciences) for $10 \mathrm{~min}$. The transfection reagent (DharaFECT) was also incubated in Opti-MEM for $10 \mathrm{~min}$ at room temperature. Following incubations, both solutions were combined and incubated for an additional $30 \mathrm{~min}$ at room temperature. The transfection solution was added to $500 \mu$ l of cell solution and incubated overnight at $37^{\circ} \mathrm{C}$. Fresh RPMI was added to the cells,
$24 \mathrm{~h}$ post-transfection. ADAM10 silencing was confirmed using reverse transcription reaction (PCR).

Cell viability assays. Cell viability was measured using direct cell counting. Following reverse transfection with $5 \times 10^{4}$ cells per well as described above, cells were trypsinised and cell suspensions were counted using the Countess Automated Cell Counter (Invitrogen Life Technologies). For assays examining the effect of GI254023X on cell numbers, $5 \times 10^{4}$ cells per well were incubated for $24 \mathrm{~h}$ and treated with either GI254023X or corresponding vehicle control for 5 days. Cells were then washed with phosphate-buffered saline (PBS) and resuspended in RPMI 1640 following the addition of trypsin. Cell suspensions were also counted using the Countess Automated Cell Counter (Invitrogen Life Technologies). Results are shown as cell numbers (\%) compared with vehicle/scrambled control-treated cells. Results are shown as mean of independent experiments carried out in triplicate \pm s.e.m.

Migration assay. Cells were seeded at a density of $5 \times 10^{4}$ cells in the upper compartment of migration inserts (Becton Dickinson, Franklin Lakes, NJ, USA). The lower chamber was filled with media containing fibroblast-conditioned media. Cells were incubated for 48 (MDA-MB-231) or $72 \mathrm{~h}$ (BT20 and MDA-MB-453). Following incubation, non-migrated cells were removed using a PBS-soaked cotton swab. In all, 1\% gluteraldehyde (Sigma, St Louis, MO, USA) was used to fix the migrated cells, followed by staining with $0.1 \%$ crystal violet (Pro-Lab Diagnostics, Chesire, UK). Migrated cells were counted using a light microscope at a magnification of $\times 20$. Five fields were counted in each well and

\begin{tabular}{|c|c|c|}
\hline Tumour characteristic & $N$ & $\%$ \\
\hline \multicolumn{3}{|l|}{ Age (years) } \\
\hline$\leqslant 50$ & 40 & 34.2 \\
\hline$>50$ & 77 & 65.8 \\
\hline Unknown & 0 & 0.0 \\
\hline \multicolumn{3}{|l|}{ Tumour size $(\mathrm{cm})$} \\
\hline$\leqslant 2$ & 32 & 27.3 \\
\hline$>2$ & 76 & 65.0 \\
\hline Unknown & 9 & 7.7 \\
\hline \multicolumn{3}{|l|}{ Grade } \\
\hline 1 and 2 & 46 & 39.3 \\
\hline & 60 & 51.3 \\
\hline Unknown & 11 & 9.4 \\
\hline \multicolumn{3}{|l|}{ Nodal status } \\
\hline Negative & 56 & 47.9 \\
\hline Positive & 56 & 47.9 \\
\hline Unknown & 5 & 4.2 \\
\hline \multicolumn{3}{|l|}{ ER status } \\
\hline Negative & 38 & 32.5 \\
\hline Positive & 79 & 67.5 \\
\hline Unknown & 0 & 0.0 \\
\hline \multicolumn{3}{|l|}{ HER2 status } \\
\hline Negative & 100 & 85.5 \\
\hline Positive & 6 & 5.1 \\
\hline Unknown & 11 & 9.4 \\
\hline \multicolumn{3}{|l|}{ Histological type $^{a}$} \\
\hline Ductal (D) & 92 & 78.6 \\
\hline Lobular (L) & 16 & 13.7 \\
\hline$D$ and $L$ & 5 & 4.3 \\
\hline Other & 0 & 0.0 \\
\hline Unknown & 4 & 3.4 \\
\hline \multicolumn{3}{|c|}{$\begin{array}{l}\text { Abbreviation: ER, oestrogen receptor. } \\
{ }^{a} \text { All tumours were infiltrating carcinomas. Ductal carcinoma in situ and lobular carcinoma } \\
\text { in situ were excluded. }\end{array}$} \\
\hline
\end{tabular}


averaged. The percentage of migrated cells was calculated compared with scrambled or vehicle control cells. Results are shown as mean of independent experiments carried out in triplicate \pm s.e.m.

Matrigel invasion assay. Similar to the migration assay described above, cells were seeded at a density of $5 \times 10^{4}$ cells per well in the upper compartment of Matrigel-coated inserts $(8 \mu \mathrm{m}$ pore size, BioCoat, BD Biosciences, Erembodegem-Dorp, Belgium). Cells were incubated for 48 or $72 \mathrm{~h}$ at $37^{\circ} \mathrm{C}$ depending on the cell line. Chambers were stained and counted in a similar manner to the migration assay.

Studies on breast tumours. Human breast tumour samples were obtained following ethical approval from the institutional board at St. Vincent's University Hospital. Following pathological evaluation, tumours were snap frozen and stored at $-80^{\circ} \mathrm{C}$. Tissue homogenisation was carried out using a Mikro-Dismembrator (Braun Biotech International, Melsungen, Germany). Protein extraction was performed as previously described (McGowan et al, 2007). Briefly, tissues were lysed with $200 \mu \mathrm{l}$ of $50 \mathrm{~mm}$ Tris$\mathrm{HCl}(\mathrm{pH}$ 7.4) containing protease inhibitors (Complete mini EDTA-free protease inhibitor cocktail, Roche Applied Science, West Sussex, UK), phosphatase inhibitors (PhosStop phosphatase inhibitor cocktail, Roche Applied Science) and Triton X-100 at a final volume of $1 \%$. This was then passed through a 19-gauge needle, vortexed and agitated for $20 \mathrm{~min}$ at $4{ }^{\circ} \mathrm{C}$. Supernatants were subsequently collected and transferred to fresh tubes. Total protein concentrations in the resulting supernatants were determined using the Nanodrop $1000 \mathrm{~A}_{280}$ program (Thermo Scientific). Clinical and pathological characteristics of the human breast cancers investigated are shown in Table 1. ADAM10 protein levels in extracts of primary breast carcinomas were measured by ELISA (USCN Life Science Inc., Wuhan, P.R. China), according to the manufacturer's instructions. For each sample, $1.5 \mathrm{mg}$ of protein was used. The relationship between ADAM10 mRNA expression and survival was investigated using the publicly available data set, BreastMark (Madden et al, 2013), as previously described (McGowan et al, 2013).

Statistical analysis. The Student's paired $t$-test was employed when determining the possible effects of either ADAM10 knockdown or ADAM10 inhibition on cell migration and invasion compared with control cells. Mann-Whitney $U$-tests were used when relating ADAM10 levels to tumour characteristics. All data were analysed using PASW Statistics Version 18 (SPSS Inc., Chicago, IL, USA) and Prism version 5.0b software (GraphPad Software, San Diego, CA, USA).

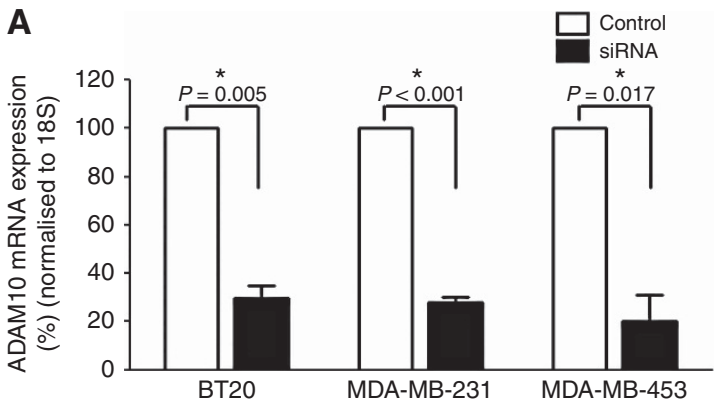

B
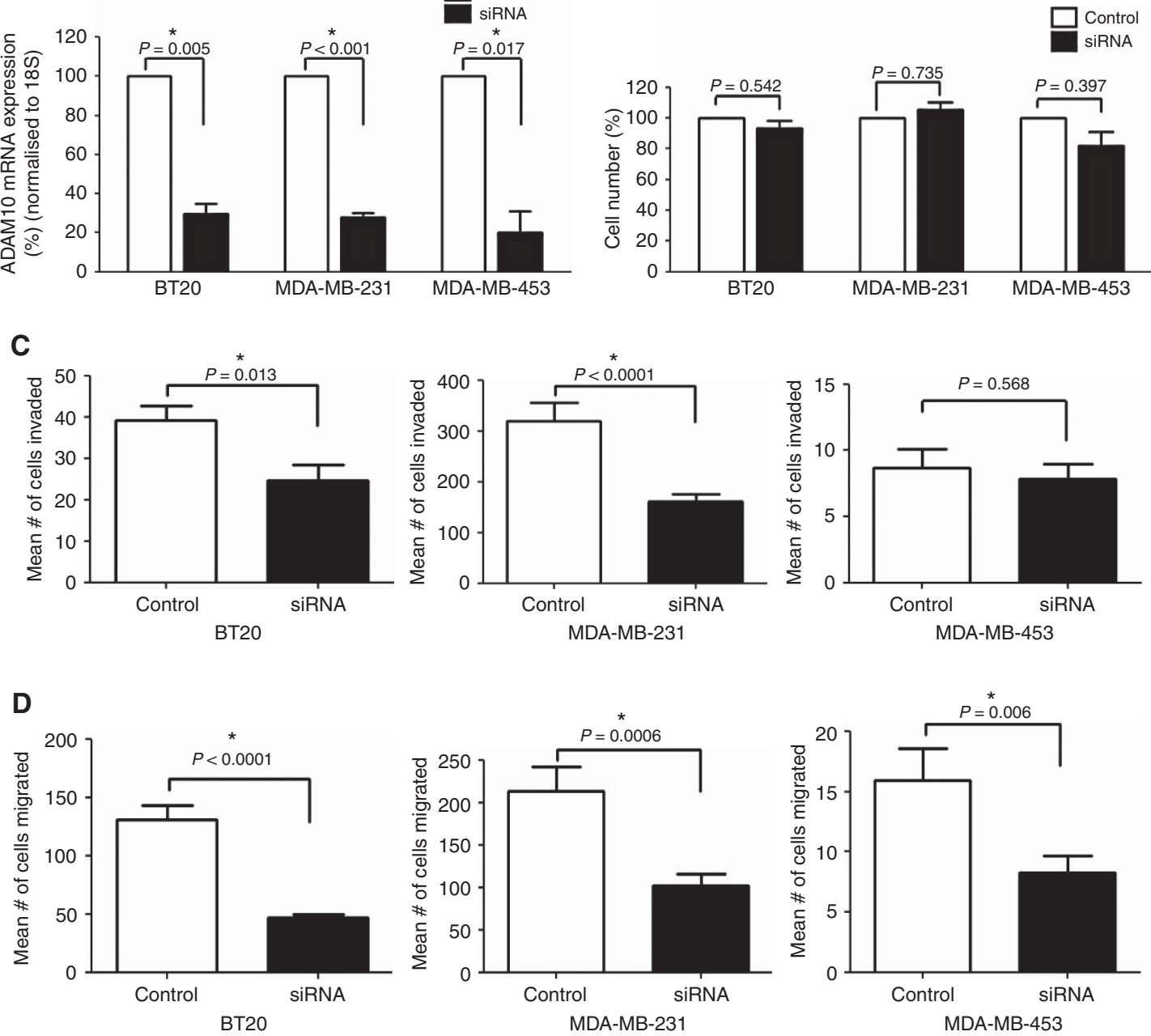

Figure 1. Effect of ADAM10 RNA interference on breast cancer cell line numbers, invasion and migration. Barchart showing the effects of decreased ADAM10 expression on BT20, MDA-MB-231 and MDA-MB-453 (A) mRNA expression, (B) cell line numbers, (C) invasion and (D) migration compared with scrambled control-treated cells. The white bars represent the control cells and the black bars represent the ADAM10 siRNA-treated cells. Data were analysed using Student's paired t-test. All experiments were carried out in triplicate. Results are means \pm s.e.m. 


\section{RESULTS}

Effect of ADAM10 knockdown on cell numbers, migration and invasion. In order to select suitable cells for ADAM10 knockdown, we first measured the endogenous expression of ADAM10 in a broad panel of breast cancer cell lines (Supplementary Figure S1). Based on this data, two TN cell lines, that is, BT20 and MDA-MB231 and one non-TN control cell line, that is, MDA-MB-453 that expressed relatively high levels of ADAM10 were selected. Following transfection of these breast cancer cell lines, expression of mRNA for the ADAM 10 was reduced by $70 \%$ in the BT 20 cells, $72 \%$ in the MDA-MB-231 cells and $80 \%$ in the MDA-MB-453 cells (Figure 1A)

Despite this decrease in mRNA for ADAM10, no significant effect was observed on breast cancer cell numbers (Figure 1B) ( $P>0.05$, for all three cell lines examined). In contrast, suppression of ADAM10 expression resulted in a significant decrease in the ability of the TN breast cancer cell lines BT20 $(P=0.013)$ and MDA-MB-231 $(P<0.0001)$ to invade through Matrigel chambers. No effect however, was observed on the ability of the non-TN cell line MDA-MB-453 $(P=0.568)$ to invade Matrigel chambers (Figure 1C). We also examined the effect of ADAM10 suppression on tumour cell Transwell migration. Downregulation of ADAM10 significantly decreased the ability of the three breast cancer cell lines to migrate through the Transwell chamber (for BT20, $P<0.0001$; for MDA-MB-231, $P=0.0006$; and for MDA-MB-453, $P=0.006$ ) (Figure 1D).
Effect of GI254023X on cell numbers, migration and invasion. We next investigated the effects of the selective ADAM10 inhibitor GI254023X $(5 \mu \mathrm{M})$ on cell numbers, migration and invasion. Similar to the effects observed with RNA interference, addition of GI254023X did not affect MDA-MB-231 $(P=0.963)$ and MDAMB-453 $(P=0.483)$ cell numbers. In contrast to siRNA-treated cells, a statistically significant but modest reduction in cell numbers was observed following treatment of the TN BT20 cell line with GI254023X (19.04 $\pm 6.62 \%, P<0.01$; Figure 2A). As with RNA interference, treatment with GI254023X significantly decreased invasion of both BT20 $(P=0.02)$ and MDA-MB-231 $(P=0.02)$ cell lines. Unlike RNA interference however, GI254023X significantly decreased invasion of the MDA-MB-453 cell line $(P=0.007$; Figure 2B). GI254023X also significantly decreased migration of these three cell lines (for BT20, $P<0.0001$; for MDA-MB-231, $P=0.005$; and for MDA-MB-453, $P=0.023$ ) (Figure 2C).

ADAM10 levels in breast cancers. ADAM10 protein levels were measured by ELISA in 117 primary breast tumour extracts. Levels varied from undetectable to $19.2 \mathrm{ng} \mathrm{mg}^{-1}$, the median value being $1.16 \mathrm{ng} \mathrm{mg}^{-1}$ protein. Levels of ADAM10 protein expression were related to established variables of tumour progression, including patient age at diagnosis, tumour size, tumour grade, lymph node status, ER status, HER2 status and histological type. Increased levels ( $>$ median) were found more frequently in higher-grade $v s$ lower-grade tumours $(P<0.001)$ and in ER-negative than in ER-positive tumours $(P=0.005)$. Significantly elevated levels of ADAM10 were detected in tumours from patients who were

A
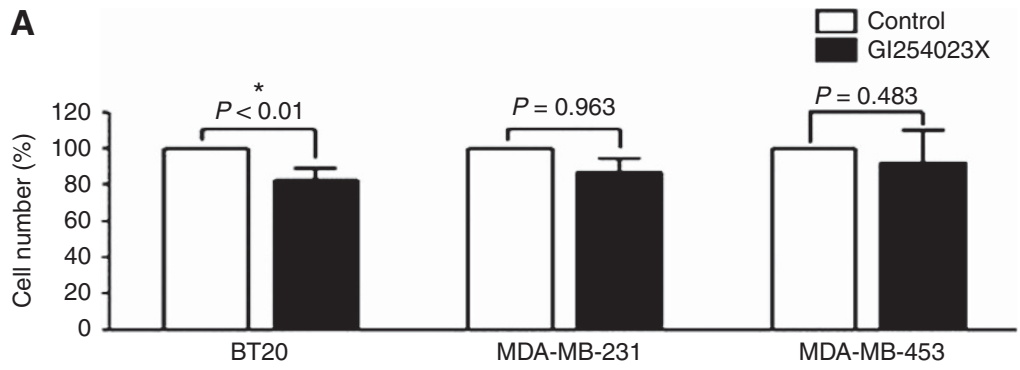

B
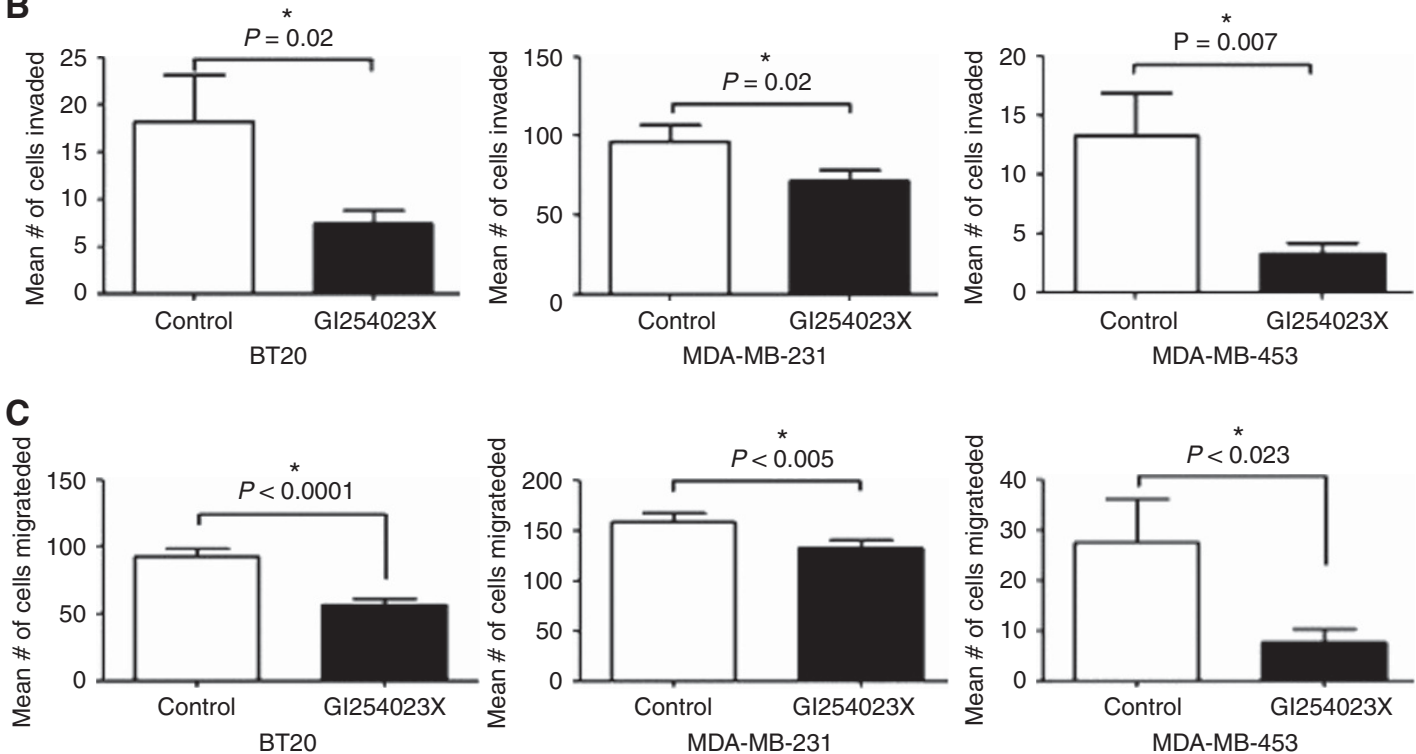

Figure 2. Effect of the ADAM10 inhibitor GI254023X on breast cancer cell line numbers, invasion and migration. Barchart showing the effects of GI254023X on BT20, MDA-MB-231 and MDA-MB-453 (A) cell line numbers, (B) invasion and (C) migration compared with vehicle control-treated cells. The white bars represent the control cells and the black bars represent GI254023X-treated cells. Data were analysed using Student's paired $t$ test. All experiments were carried out in triplicate. Results are means \pm s.e.m. 
younger than 50 years at diagnosis compared with those who were older $(P=0.018)$. In contrast, no significant associations were found between ADAM10 protein levels and tumour size, lymph node status, HER2 status or histological subtype (Table 2).

ADAM10 levels and patient outcome. In order to establish whether ADAM10 levels predicted patient outcome, we analysed its expression using cutoffs at the median expression level in a cohort of pooled publicly available data sets $(n=2592$; Madden et al, 2013). ADAM10 was categorised as the expression

Table 2. Relationship between ADAM10 protein expression and variables of tumour progression

\begin{tabular}{|c|c|c|c|}
\hline Tumour characteristic & $N$ & $\begin{array}{c}\text { Median ADAM10 } \\
\text { protein levels } \\
\left(\mathrm{ng} \mathrm{mg}^{-1}\right)\end{array}$ & $P$-value \\
\hline \multicolumn{4}{|l|}{ Age (years) } \\
\hline $\begin{array}{l}\leqslant 50 \\
>50\end{array}$ & $\begin{array}{l}40 \\
77\end{array}$ & $\begin{array}{l}1.73 \\
1.08\end{array}$ & 0.018 \\
\hline \multicolumn{4}{|l|}{ Tumour size $(\mathrm{cm})$} \\
\hline $\begin{array}{l}\leqslant 2 \\
>2\end{array}$ & $\begin{array}{l}32 \\
76\end{array}$ & $\begin{array}{l}1.07 \\
1.20\end{array}$ & 0.315 \\
\hline \multicolumn{4}{|l|}{ Grade } \\
\hline $\begin{array}{l}1 \text { and } 2 \\
3\end{array}$ & $\begin{array}{l}46 \\
60\end{array}$ & $\begin{array}{l}0.84 \\
1.74\end{array}$ & $<0.001$ \\
\hline \multicolumn{4}{|l|}{ Nodal status } \\
\hline $\begin{array}{l}0 \\
1-3 \\
4-9 \\
>10\end{array}$ & $\begin{array}{r}56 \\
30 \\
15 \\
9\end{array}$ & $\begin{array}{l}1.64 \\
0.84 \\
1.08 \\
1.13\end{array}$ & $0.146^{b}$ \\
\hline \multicolumn{4}{|l|}{ ER status } \\
\hline $\begin{array}{l}\text { Negative } \\
\text { Positive }\end{array}$ & $\begin{array}{l}38 \\
79\end{array}$ & $\begin{array}{l}1.79 \\
1.08\end{array}$ & 0.005 \\
\hline \multicolumn{4}{|l|}{ HER2 status } \\
\hline $\begin{array}{l}\text { Negative } \\
\text { Positive }\end{array}$ & $\begin{array}{r}100 \\
6\end{array}$ & $\begin{array}{l}1.08 \\
1.54\end{array}$ & 0.452 \\
\hline \multicolumn{4}{|l|}{ Histological type } \\
\hline $\begin{array}{l}\text { Ductal (D) } \\
\text { Lobular (L) } \\
\text { D and L }\end{array}$ & $\begin{array}{r}92 \\
16 \\
5 \\
\end{array}$ & $\begin{array}{l}1.18 \\
1.02 \\
1.03\end{array}$ & $0.496^{b}$ \\
\hline $\begin{array}{l}\text { Abbreviation: ER, oestrogen re } \\
{ }^{2} \text { Data were analysed using the } \\
\text { b }_{\text {Data were analysed using Kru }}\end{array}$ & $\begin{array}{l}\text { or. } \\
\text { n-Whit } \\
\text { Wallis a }\end{array}$ & $\begin{array}{l}\text { U-test. } \\
\text { ysis. }\end{array}$ & \\
\hline
\end{tabular}

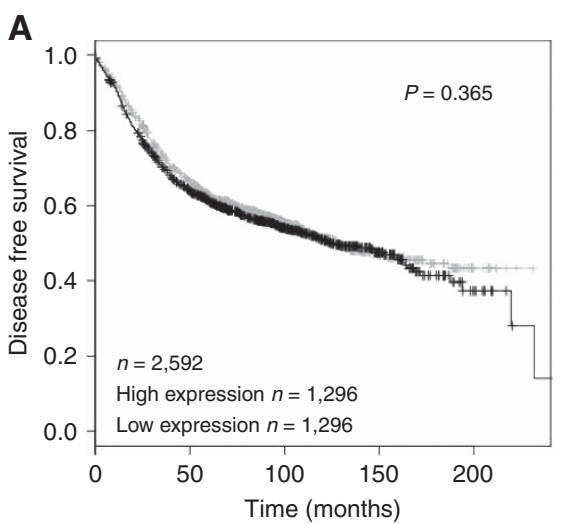

greater than or less than the median ADAM10 expression level. Although, no significant relationship was found between ADAM10 mRNA levels (median cutoff) and disease-free survival in the total population of patients (hazard ratio $=1.01 ; P=0.365$; Figure $3 \mathrm{~A}$ ), increased ADAM10 expression predicted disease-free survival in the basal subgroup of patients (hazard ratio $=1.57(1.18-2.09$ ); $P=1.83 \times 10^{-4}$; Figure $3 \mathrm{~B}$ ). In contrast to this finding in the basal subtype, ADAM10 expression was not associated with outcome in either the luminal or HER2-positive subtypes (data not shown).

\section{DISCUSSION}

To our knowledge, this is one of the most comprehensive reports to date on ADAM10 in any malignancy. Using three different breast cancer cell lines, we show using both RNAi knockdown and a selective low molecular inhibitor that ADAM10 is involved in cell migration. In contrast, our results suggest that ADAM10 does not reduce cell numbers, at least in two of the three cell lines investigated in our study. With the BT20 cell line however, although ADAM10 knockdown failed to affect cell counts, treatment with GI254023X had a modest impact in reducing cell numbers, that is, by $19 \%$, a finding that was not observed in the MDA-MB-231 cell line. The biological relevance of such a modest reduction in cell numbers is unclear. The most likely explanation for the different effects of ADAM10 knockdown and GI254023X in the BT20 cell is that the low molecular weight inhibitor is not only absolutely specific for ADAM10 but may also be marginally impacting on a pathway having a role in cell proliferation or viability.

Previously, Arima et al (2007) reported that decreased ADAM10 expression in a prostate cancer cell line blocked growth on only 1 of the 4 days in which this end point was determined. However, following stimulation with dihydrotestosterone, decreased growth was found on 2 of the 4 days. In another in vitro study, Lee et al (2010) showed that downregulation of ADAM10 expression in melanoma cells resulted in both suppression of anchorage-independent cell growth and reduced migration. Similar to our findings with breast cancer cell lines, Gaida et al (2010), using pancreatic cancer cells, reported that downregulation of ADAM10 failed to decrease cell proliferation but led to reduced invasion and migration. Thus the effects of ADAM10 may be variable, depending on the cell type.

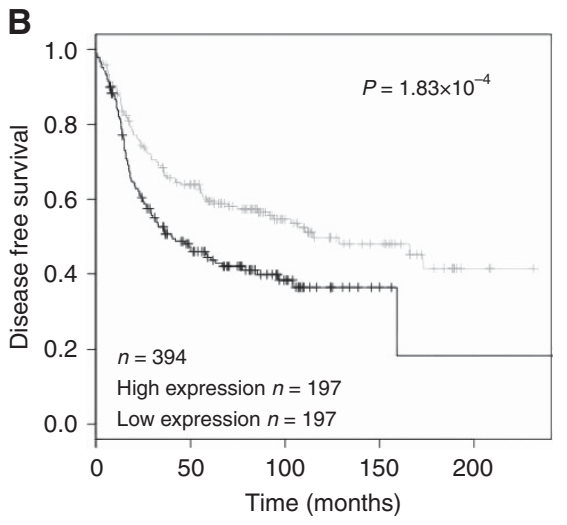

Figure 3. Relationship between ADAM10 mRNA expression and disease-free survival in the basal-like breast cancer subgroup. Kaplan-Meier curves showing the association between ADAM10 mRNA expression and disease-free survival using the default settings of BreastMark (Madden et al, 2013) (A) across all molecular subtypes of breast cancer and (B) in the basal-like breast cancer patient subtype. High expression is shown in black and low expression is shown in grey. All survival analysis was carried out using the publicly available data set BreastMark (Madden et al, 2013). Data were analysed using the Log Rank test and Kaplan-Meier analysis. 
How ADAM10 promotes in vitro breast cancer cell invasion or migration in our study is not clear. However, as mentioned in the Introduction above, ADAM10 is known to cleave E-cadherin (Maretzky et al, 2005a; Solanas et al, 2011). Using fibroblasts and keratinocytes, Maretzky et al (2005b) showed that ADAM10mediated cleavage of E-cadherin resulted in altered cell-cell adhesion and enhanced invasion. This effect on E-cadherin, however, may also be cell-type dependent, as ADAM10 siRNAtreated pancreatic cancer cell lines displayed no alteration in E-cadherin protein levels (Gaida et al, 2010). Other potential mechanisms by which ADAM10 could promote migration and invasion include cleavage of membrane proteins such as $\mathrm{N}$-cadherin (Reiss et al, 2005), L1 (Mechtersheimer et al, 2001; Maretzky et al, 2005b) or CD44 (Murai et al, 2006). Alternatively, ADAM10 could promote invasion and migration via activation of the EGFR ligands, betacellulin and EGF.

Consistent with a role in invasion/migration, we found that high levels of ADAM10 in the extracts of breast cancer correlated with indices of aggressive disease, such as ER-negativity and high tumour grade. Perhaps, more importantly, we showed that high ADAM10 mRNA levels were associated with adverse outcome in patients with the basal subform of breast cancer. Seventy to $80 \%$ of basal breast cancer lack ER, progesterone receptors and HER2 and are thus referred to as TN breast cancer (TNBC) (Duffy et al, 2012). Consequently, most patients with basal breast cancer are unable to receive a targeted therapy. This inability to be treated with a targeted therapy when combined with their intrinsic aggressiveness and lack of a validated prognostic marker means that patients with TNBC tend to have a poor outcome (Duffy et al, 2012). Unfortunately, it was not possible to evaluate a potential prognostic impact for ADAM10 in TNBC in our pooled collection of databases as too few of the patients had data on HER2 gene amplification/overexpression.

Our results suggest that ADAM10 mRNA may be a new prognostic biomarker for this subgroup of patients with breast cancer. Indeed, as ADAM10 correlates with outcome in basal-type breast cancer, it may be involved in their progression and thus function as a therapeutic target for these patients. If confirmed, the selective ADAM10 inhibitor used in the present investigation, that is, GI254023X, could be a potential treatment for basal carcinoma. GI254023X should thus now be investigated for efficacy and toxicity in an animal model of basal breast cancer.

Although the main focus of our work was on ADAM10 in TN and basal breast cancer, as mentioned in the Introduction above, Feldinger et al (2014) recently reported that increased expression of this ADAM was associated with resistance to Herceptin. Furthermore, high levels of ADAM10 predicted adverse patient outcome (Feldinger et al, 2014). In our study however, ADAM10 was not associated with outcome in HER2-positive patients. These different findings with ADAM10 may relate to different treatments administered in the two studies.

Before concluding, it is important to point out limitations in this report. First, although substantial knockdown of ADAM10 was observed at the mRNA levels, we did not confirm this at the protein level. Furthermore, we used a pooled mixture of four ADAM10 siRNA sequences to target ADAM10. Although the use of such a pooled mixture is likely to result in greater knockdown of ADAM10 expression than use of a single species, it could potentially increase the likelihood of off-target effects.

In addition, although we showed that high ADAM10 mRNA levels predicted a shortened disease-free interval in patients with basal-type breast cancer, we have not confirmed this at a protein level. As basal breast cancer constitute only approximately $15-20 \%$ of all breast cancer, a large total population of patients with breast cancer is necessary to obtain an adequate number of the basaltype samples for performing outcome studies. To address this problem, we used a publicly available database derived from
12 independent studies and containing 2718 patients (Madden et al, 2013). To our knowledge, a similar database for protein expression is currently not available. A further limitation of our study is that we did not investigate the effects of ADAM10 knockdown on cell numbers, migration and invasion at multiple time points.

In conclusion, our results suggest that ADAM10 may be a new player in breast cancer progression, especially in mediating invasion and migration. Inhibition of ADAM10 might thus be used to block these processes and thus prevent breast cancer progression. Indeed, as ADAM10 was particularly associated with adverse outcome in patients with basal breast cancer, it may be a new therapeutic target for the treatment of this form of the disease.

\section{ACKNOWLEDGEMENTS}

We thank Science Foundation Ireland, Strategic Research Cluster Award (08/SRC/B1410) to Molecular Therapeutics for Cancer Ireland, the Irish Cancer Society Collaborative Cancer Research Centre BREAST-PREDICT programme (CCRC13GAL), the Cancer Research Ireland Postdoctoral Fellowship (CRF11MCG), the Health Research Board Clinician Scientist Award (CSA/2007/ 11), the Cancer Clinical Research Trust and the European Union FP7 Grant No. 278568 "PRIMES" for funding this work.

\section{CONFLICT OF INTEREST}

The authors declare no conflict of interest.

\section{REFERENCES}

Arima T, Enokida H, Kubo H, Kagara I, Matsuda R, Toki K, Nishimura H, Chiyomaru T, Tatarano S, Idesako T, Nishiyama K, Nakagawa M (2007) Nuclear translocation of ADAM-10 contributes to the pathogenesis and progression of human prostate cancer. Cancer Sci 98: 1720-1726.

Blobel CP (2005) ADAMs: key components in EGFR signalling and development. Nat Rev Mol Cell Biol 6: 32-43.

Borrell-Pages M, Rojo F, Albanell J, Baselga J, Arribas J (2003) TACE is required for the activation of the EGFR by TGF-alpha in tumors. EMBO J 22: 1114-1124.

Bozhulak EC, Weinmaster G (2009) Selective use of ADAM10 and ADAM17 in activation of Notch 1 signaling. Mol Cell Biol 29: 5679-5695.

Duffy MJ, McGowan PM, Crown J (2012) Targeted therapy for triple-negative breast cancer: where are we? Int J Cancer 131: 2471-2477.

Duffy MJ, McKiernan E, O’Donovan N, McGowan PM (2009) Role of ADAMs in cancer formation and progression. Clin Cancer Res 15: 1140-1144.

Duffy MJ, Lynn DJ, Lloyd AT, O'Shea CM (2003) The ADAMs family of proteins: from basic studies to potential clinical applications. Thromb Haemostat 89: 622-631.

Feldinger K, Generali D, Kramer-Marek G, Gijsen M, Ng TB, Wong JH, Strina C, Cappelletti M, Andreis D, Li JL, Bridges E, Turley H, Leek R, Roxanis I, Capala J, Murphy G, Harris AL, Kong A (2014) ADAM10 mediates trastuzumab resistance and is correlated with survival in HER2 positive breast cancer. Oncotarget 5: 6633-6646.

Franovic A, Robert I, Smith K, Kurban G, Pause A, Gunaratnam L, Lee S (2006) Multiple acquired renal carcinoma tumor capabilities abolished upon silencing of ADAM17. Cancer Res 66: 8083-8090.

Gaida MM, Haag N, Günther F, Tschaharganeh DF, Schirmacher P, Friess H, Giese NA, Schmidt J, Wente MN (2010) Expression of A disintegrin and metalloprotease 10 in pancreatic carcinoma. Int J Mol Med 26: $281-288$.

Hartmann D, de Strooper B, Serneels L, Craessaerts K, Herreman A, Annaert W, Umans L, Lübke T, Lena Illert A, von Figura K, Saftig P (2002) The disintegrin/metalloprotease ADAM 10 is essential for Notch signalling but not for alpha-secretase activity in fibroblasts. $\mathrm{Hum} \mathrm{Mol}$ Genet 11: 2615-2624. 
Hundhausen C, Misztela D, Berkhout TA, Broadway N, Saftig P, Reiss K, Hartmann D, Fahrenholz F, Postina R, Matthews V, Kallen KJ, Rose-John S, Ludwig A (2003) The disintegrin-like metalloproteinase ADAM10 is involved in constitutive cleavage of CX3CL1 (fractalkine) and regulates CX3CL1-mediated cell-cell adhesion. Blood 102: 1186-1195.

Kenny PA, Bissell MJ (2007) Targeting TACE-dependent EGFR ligand shedding in breast cancer. J Clin Invest 117: 337-345.

Lee SB, Schramme A, Doberstein K, Dummer R, Abdel-Bakky MS, Keller S, Altevogt P, Oh ST, Reichrath J, Oxmann D, Pfeilschifter J, Mihic-Probst D, Gutwein P (2010) ADAM10 is upregulated in melanoma metastasis compared with primary melanoma. J Invest Dermatol 130: 763-773.

Ludwig A, Hundhausen C, Lambert MH, Broadway N, Andrews RC, Bickett DM, Leesnitzer MA, Becherer JD (2005) Metalloproteinase inhibitors for the disintegrin-like metalloproteinases ADAM10 and ADAM17 that differentially block constitutive and phorbol ester-inducible shedding of cell surface molecules. Comb Chem High Throughput Screen 8: 161-171.

Madden SF, Clarke C, Gaule P, Aherne ST, O’Donovan N, Clynes M, Crown J, Gallagher WM (2013) BreastMark: an integrated approach to mining publicly available transcriptomic datasets relating to breast cancer outcome. Breast Cancer Res 15: R52.

Maretzky T, Reiss K, Ludwig A, Buchholz J, Scholz F, Proksch E, de Strooper B, Hartmann D, Saftig P (2005a) ADAM10 mediates E-cadherin shedding and regulates epithelial cell-cell adhesion, migration, and $\beta$-catenin translocation. Proc Natl Acad Sci USA 102: 9182-9187.

Maretzky T, Schulte M, Ludwig A, Rose-John S, Blobel C, Hartmann D, Altevogt P, Saftig P, Reiss K (2005b) L1 is sequentially processed by two differently activated metalloproteases and presenilin/gamma-secretase and regulates neural cell adhesion, cell migration, and neurite outgrowth. Mol Cell Biol 25: 9040-9053.

McGowan PM, Mullooly M, Caiazza F, Sukor S, Madden SF, Maguire AA, Pierce A, McDermott EW, Crown J, O’Donovan N, Duffy MJ (2013) ADAM-17: a novel therapeutic target for triple negative breast cancer. Ann Oncol 24: 362-369.

McGowan PM, Ryan BM, Hill AD, McDermott E, O’Higgins N, Duffy MJ (2007) ADAM-17 expression in breast cancer correlates with variables of tumor progression. Clin Cancer Res 13: 2335-2343.
Mechtersheimer S, Gutwein P, Agmon-Levin N, Stoeck A, Oleszewski M, Riedle S, Postina R, Fahrenholz F, Fogel M, Lemmon V, Altevogt P (2001) Ectodomain shedding of $\mathrm{L} 1$ adhesion molecule promotes cell migration by autocrine binding to integrins. J Cell Biol 155: 661-673.

Moss ML, Stoeck A, Yan W, Dempsey PJ (2008) ADAM10 as a target for anti-cancer therapy. Curr Pharm Biotechnol 9: 2-8.

Murai T, Miyauchi T, Yanagida T, Sako Y (2006) Epidermal growth factor-regulated activation of Rac GTPase enhances CD44 cleavage by metalloproteinase disintegrin ADAM10. Biochem J 395: 65-71.

Murphy G (2008) The ADAMs: Signalling scissors in the tumour microenvironment. Nat Rev Cancer 9: 929-941.

Reiss K, Maretzky T, Ludwig A, Tousseyn T, de Strooper B, Hartmann D, Saftig P (2005) ADAM10 cleavage of N-cadherin and regulation of cell-cell adhesion and beta-catenin nuclear signalling. EMBO J 24: $742-752$.

Sahin U, Blobel CP (2007) Ectodomain shedding of the EGF-receptor ligand epigen is mediated by ADAM17. FEBS Lett 581: 41-44.

Sahin U, Weskamp G, Kelly K, Zhou HM, Higashiyama S, Peschon J, Hartmann D, Saftig P, Blobel CP (2004) Distinct roles for ADAM10 and ADAM17 in ectodomain shedding of six EGFR ligands. J Cell Biol 164: 769-779.

Solanas G, Cortina C, Servillano M, Batlle E (2011) Cleavage of E-cadherin by ADAM10 mediates epithelial cell sorting downstream of EphB signalling. Nat Cell Biol 13: 1100-1107.

Weber S, Niessen MT, Prox J, Lüllmann-Rauch R, Schmitz A, Schwanbeck R, Blobel CP, Jorissen E, de Strooper B, Niessen CM, Saftig P (2011) The disintegrin/metalloproteinase Adam10 is essential for epidermal integrity and Notch-mediated signaling. Development 138: 495-505.

This work is published under the standard license to publish agreement. After 12 months the work will become freely available and the license terms will switch to a Creative Commons AttributionNonCommercial-Share Alike 4.0 Unported License.

Supplementary Information accompanies this paper on British Journal of Cancer website (http://www.nature.com/bjc) 